\title{
Photodynamic therapy with verteporfin in paediatric and young adult patients: long-term treatment results of choroidal neovascularisations
}

\author{
A Lipski, N Bornfeld, B Jurklies
}

Department of Ophthalmology, University Hospital Essen, Essen, Germany

Correspondence to:

Dr A Lipski, Department of Ophthalmology,

Universitätsklinikum Essen,

Hufelandstraße 55, D-45122

Essen, Germany; andreas.

lipski@uni-duisburg-essen.de

Accepted 20 January 2008 Published Online First

20 March 2008

\begin{abstract}
Background: Vision impairment in children and young adults may derive from choroidal neovascularisation (CNV) related to numerous conditions. The aim of this study is to highlight the applicability of photodynamic therapy using verteporfin (PDT) in these patients.

Methods: In 16 eyes of 16 consecutive patients aged 30 years or younger, prospective open-label PDT was performed. Outcomes of visual acuity as well as changes in CNV lesion parameters were evaluated.
\end{abstract}

Results: The mean patient age at first PDT was 19.7 (SD 8.7) years (range $6-30$ ). $81 \%$ of the patients retained stable vision within two lines or exceedingly improved vision during follow-up of 34 (24) months. Significant vision gain was denoted in seven paediatric patients (2.7 (1.4) lines, mean (SD); $p=0.019$ ) as well as in a subgroup of 12 patients not affected by active uveitis (2.6 (2.0) lines, $p=0.0005$ ). Two patients with multifocal choroiditis and panuveitis (MCP) experienced vision losses of five and 11 lines after four PDT sessions despite receiving additional steroidal treatment. Except for one patient with MCP and two patients who dismissed followup, a mean of 2.2 (1.3) PDTs per patient sufficiently inactivated CNV lesions during follow-up. In the area of the former PDT spot, alterations of the pigment epithelium increased by $40 \%$ without correlation to changes in vision. Conclusions: The results indicate good PDT efficacy and tolerability most promising in a subgroup of patients with vision-impairing CNV not associated with active uveitis. PDT in young patients with CNV remains a valuable treatment with good risk-benefit profile over the long term.

Choroidal neovascularisation (CNV) may develop in children and young adults due to pathological myopia, the presumed ocular histoplasmosis syndrome (POHS), retinochoroiditis as well as secondary to angioid streaks, trauma or idiopathically. ${ }^{1-3}$ Within these disease groups, healing and treatment responses may be influenced by age-dependent mechanisms. ${ }^{4}$ A therapy proven in adults could therefore be expected to be either less or even more effective in young individuals. It may thus be valuable to separately prove the effectiveness of $\mathrm{CNV}$ treatment in patients younger than 30 years of age. ${ }^{4-6}$

Among the approaches of CNV treatment, laser photocoagulation and photodynamic therapy with verteporfin (PDT) besides surgical CNV extraction have currently been considered. ${ }^{7-15}$ More recently, intravitreal injections of agents antagonising the binding activity of the vascular endothelial growth factor family have been extending the therapeutic armament. ${ }^{16-19}$

Perspectives for young patient care must exceedingly focus on healing strategies. This implies the proposition of CNV inactivation by means of maximum efficacy and avoidance of procedurerelated risks. Photodynamic therapy using verteporfin in adults is a well-established and safe treatment for CNV related to various causes. ${ }^{413}$ 20-25 Probably due to the overall low incidence of CNV in young patients, the efficacy and safety of PDT in paediatric or young adult patients have been subject to analysis in only a few reports so far. ${ }^{5615}$ In this prospective interventional open-label study, we followed courses of PDT treatment over the long term to verify its applicability in paediatric and younger patients with CNV.

\section{PATIENTS AND METHODS}

We analysed CNV treatment courses of patients younger than 31 years of age at initial PDT treatment in our clinic between 1999 and 2006. Active CNV leakage and symptomatic vision impairment had to be present before the first PDT. No further exclusion criteria regarding vision or CNV localisation were implemented. We excluded eyes with previously performed laser photocoagulation. PDT-treated patients secondary to angioma formation and $\mathrm{CNV}$ due to angioid streaks were not eligible to follow-up, as either outcomes have already been described separately or patients were beyond the age of 30 years at initial treatment. ${ }^{25}{ }^{26}$ The diagnosis of CNV secondary to toxoplasmic chorioretinitis was guided by ophthalmoscopic and angiographic detection of CNV adjacent to "punched out" pigmented atrophic chorioretinal scars. Serological verification of toxoplasmosis as a cause of CNV was performed in two out of 16 patients using ELISA (IgG $>100 \mathrm{U} /$ $\mathrm{ml})$.

Ophthalmological examination included bestcorrected visual acuity testing, tonometry, ophthalmoscopy, photography and fluorescein angiography using standard techniques. Best-corrected visual acuity (VA) was examined using Landolt optotypes at a distance of $5 \mathrm{~m}$ (Snellen, DIN 58220) and converted to $\log (M A R)$ for statistical analyses.

Measurements of linear lesion diameters were performed on standardised $30^{\circ}$ printouts of respective HRA II-angiograms (Heidelberg Engineering, Heidelberg, Germany). ${ }^{27}$ Parameters of angiographic lesion identification and measurement 
included the greatest linear dimension measure (GLD), which encompasses the wet lesion borders including haemorrhages, pigment epithelial detachment as well as CNV with its hypofluorescent margins or, if present, scarring, respectively. ${ }^{27}$ Additionally, the pigment epithelial lesion diameter (PLD) outlines any homogenous area of dry stippled or plane angiographic hyperfluorescence due to pigment epithelial atrophy which may be interspersed by fine mottling of pigmentation. The choroidal neovascular lesion diameter was indicated as CLD. It encounters the CNV lesion including its hypofluorescent margins during the early- or midphase angiogram. Classic CNV was characterised by a well-demarcated area of hyperfluorescence in the early phases with leakage through the mid and late phases which obscures the boundaries of this area.

PDT treatment was applied using the following conditions: after infusing Verteporfin (Visudyne, Novartis, Basel, Switzerland) intravenously over $10 \mathrm{~min}\left(6 \mathrm{mg} / \mathrm{m}^{2}\right.$ body surface area in a volume of $30 \mathrm{ml}), 50 \mathrm{~J} / \mathrm{m}^{2}$ of light was applied using a $689 \mathrm{~nm}$ diode laser (Zeiss, Germany) at an intensity of $600 \mathrm{~mW} / \mathrm{cm}^{2}$ using a contact lens (Volk, Mentor, OH). The laser spot size was selected by adding a $500 \mu \mathrm{m}$ safety diameter to fully cover the estimated GLD. Treatment was repeated after 3 months if fluorescein angiography revealed persistent leakage activity of the CNV.

Statistical evaluation was performed using a two-sided Student $t$ test (level of significance $=5 \%$ ). Values represent mean (SD) except otherwise indicated. Correlations were analysed using Pearson's method.

\section{RESULTS}

Sixteen patients have been enrolled into the study. Nine patients exhibited CNV related to POHS, three patients had
CNV related to pathological myopia, and four patients showed CNV formation secondary to toxoplasmosis or multifocal choroiditis and panuveitis (MCP, table 1). The mean patient age at first PDT was 19.7 (8.7) years (range: 6-30). No injection site-related complications were recorded, and PDT was well tolerated. Only during fluorescein angiography did one patient develop mild allergic skin reactions after intravenous application of diagnostic fluorescein solution. Two patients of the POHS subgroup declined follow-up after 3 and 6 months because of personal preferences for alternative treatments (homeopathy and acupuncture). A pregnant patient with POHS declined PDT treatment as well as angiography. PDT treatment was again performed after ablactation.

Figure $1 \mathrm{~A}, \mathrm{~B}$ and table 1 show the courses of VA during the follow-up period of 34 (24) months (range: 3-85) and a mean number of 2.19 (1.3) PDT sessions. In the total cohort, longitudinal VA testing revealed a statistically insignificant increase from $\log (\mathrm{MAR})=0.60(0.35)$ before the first PDT to $0.49(0.39)$ at the end of follow-up which was equal to a mean gain of 1.13 (4.10) lines $(p=0.1, n=16)$. Improvement of vision of at least two lines was observed in 11 patients (69\%), while two patients remained stable (12\%). A decrease in VA was noted in three patients (19\%) with a loss of 2, 5 and 11 lines, respectively.

Separate analysis of the seven paediatric patients (no. 1, 4, 7, $10,12,13,14)$ in the different subgroups revealed statistically significant mean improvements of 2.7 (1.4) lines (from mean $\log (\mathrm{MAR})=0.69(0.43)$ to $0.43(0.29), \mathrm{p}<0.02)$ after 2.4 (1.3) PDT sessions and 37 (24) months follow-up. Patients with follow-up periods of longer than 24 months ( $\mathrm{n}=7$; no. 7, 8, 11, $12,13,15,16)$ retained stable vision (from mean $\log (\mathrm{MAR})=0.45(0.25)$ to $0.48(0.48), \mathrm{p}=0.9)$ after 2.6 (1.6) PDT sessions and 56 (21) months follow-up.

Table 1 Patient and lesion characterisics of the subgroups presumed ocular histoplasmosis syndrome (POHS) $(\mathrm{n}=9)$, multifocal choroiditis and panuveitis/toxoplasmosis $(n=4)$ and myopia $(n=3)$

\begin{tabular}{|c|c|c|c|c|c|c|c|c|c|c|c|c|c|c|c|c|}
\hline \multirow[b]{2}{*}{ Pt. no. } & \multirow[b]{2}{*}{ Gender } & \multirow[b]{2}{*}{ Eye } & \multirow{2}{*}{$\begin{array}{l}\text { CNV } \\
\text { location }\end{array}$} & \multirow{2}{*}{$\begin{array}{l}\text { CNV } \\
\text { type }\end{array}$} & \multirow{2}{*}{$\begin{array}{l}\text { CNV } \\
\text { cause }\end{array}$} & \multirow{2}{*}{$\begin{array}{l}\text { Follow-up } \\
\text { (months) }\end{array}$} & \multirow{2}{*}{$\begin{array}{l}\text { Age } \\
\text { (years) }\end{array}$} & \multirow{2}{*}{$\begin{array}{l}\text { PDT } \\
\text { (no.) }\end{array}$} & \multicolumn{2}{|c|}{ Log(MAR) } & \multirow{2}{*}{$\begin{array}{l}\Delta V A \\
\text { (lines) }\end{array}$} & \multirow{2}{*}{$\begin{array}{l}\text { PLD pre } \\
(\mu \mathrm{m})\end{array}$} & \multirow{2}{*}{$\begin{array}{l}\text { PLD last } \\
(\mu \mathrm{m})\end{array}$} & \multirow{2}{*}{$\begin{array}{l}\text { GLD pre } \\
(\mu \mathrm{m})\end{array}$} & \multirow{2}{*}{$\begin{array}{l}\text { GLD last } \\
(\mu \mathrm{m})\end{array}$} & \multirow{2}{*}{$\begin{array}{l}\text { CLD pre } \\
(\mu \mathrm{m})\end{array}$} \\
\hline & & & & & & & & & VA pre & VA last & & & & & & \\
\hline 1 & $\mathrm{~F}$ & OD, B & Subfov & Class & POHS & 18 & 11 & 3 & 0.7 & 0.3 & 4 & 1800 & 1800 & 1800 & 800 & 1800 \\
\hline 2 & $\mathrm{~F}$ & OS & Juxtafov & Class & POHS & 19 & 23 & 3 & 0.6 & 0.4 & 2 & 1400 & 2400 & 1400 & 2400 & 1400 \\
\hline 3 & $\mathrm{~F}$ & OS, B & Subfov & Class & POHS & 3 & 29 & 1 & 0.6 & 0.8 & -2 & 2100 & 3000 & 4600 & 1600 & 2100 \\
\hline 4 & $\mathrm{~F}$ & OD & Subfov & Class & POHS & 18 & 8 & 1 & 1.5 & 1.0 & 3 & 3800 & 5400 & 3800 & 3800 & 3800 \\
\hline 5 & $\mathrm{~F}$ & $\mathrm{OD}$ & Subfov & Class & POHS & 18 & 29 & 1 & 0.3 & 0.0 & 2 & 850 & 1200 & 900 & 600 & 900 \\
\hline 6 & $\mathrm{~F}$ & OD & Subfov & Class & POHS & 6 & 24 & 1 & 0.9 & 0.7 & 2 & 2000 & 2500 & 3000 & 2500 & 2000 \\
\hline 7 & $\mathrm{~F}$ & $\mathrm{OD}$ & Subfov & Class & POHS & 85 & 6 & 2 & 1.0 & 0.5 & 6 & 3800 & 4100 & 3800 & 4100 & 4000 \\
\hline 8 & $\mathrm{~F}$ & os & Subfov & Class & POHS & 62 & 28 & 1 & 0.5 & 0.0 & 5 & 1100 & 2780 & 1900 & 1900 & 1100 \\
\hline 9 & $\mathrm{M}$ & $\mathrm{OD}$ & Subfov & Class & POHS & 23 & 18 & 2 & 1.0 & 0.7 & 3 & 800 & 1500 & 800 & 600 & 800 \\
\hline 10 & $\mathrm{M}$ & OS, B & Subfov & Class & Myopia & 23 & 13 & 3 & 0.8 & 0.6 & 2 & 2600 & 2700 & 800 & 900 & 800 \\
\hline 11 & $\mathrm{~F}$ & OS & Subfov & Class & Myopia & 80 & 31 & 1 & 0.5 & 0.3 & 2 & 1700 & 2800 & 2000 & 1500 & 1200 \\
\hline \multirow[t]{2}{*}{12} & $\mathrm{M}$ & OS, B & Extrafov & Class & myopia & 35 & 15 & 1 & 0.2 & 0.0 & 2 & 1100 & 1100 & 1000 & 600 & 900 \\
\hline & & & & $\mathrm{n}=12$ & Mean (SD) & $32(28)$ & $\begin{array}{l}19.9 \\
(8.8)\end{array}$ & $\begin{array}{c}1.7 \\
(0.9)\end{array}$ & $\begin{array}{c}0.76 \\
(0.31)\end{array}$ & $\begin{array}{l}0.48 * * \\
(0.30)\end{array}$ & $\begin{array}{c}2.6 \\
(1.9)\end{array}$ & $\begin{array}{l}1921 \\
(985)\end{array}$ & $\begin{array}{l}2607 * * \\
(1171)\end{array}$ & $\begin{array}{c}2150 \\
(1274)\end{array}$ & $\begin{array}{c}1775 \\
(1169)\end{array}$ & $\begin{array}{c}1733 \\
(1062)\end{array}$ \\
\hline 13 & $\mathrm{~F}$ & OS & Subfov & Class & Toxo & 59 & 10 & 5 & 0.3 & 0.3 & 0 & 2600 & 4000 & 3200 & 2200 & 2300 \\
\hline 14 & $\mathrm{~F}$ & OD & Extrafov & Class & Toxo & 23 & 13 & 2 & 0.3 & 0.3 & 0 & 1500 & 2800 & 3200 & 1100 & 1700 \\
\hline $15^{*}$ & $\mathrm{M}$ & OS & Subfov & Class & MCP & 27 & 30 & 4 & 0.2 & 0.7 & -5 & 900 & 3300 & 900 & 1800 & 900 \\
\hline \multirow[t]{2}{*}{$16 \dagger$} & $\mathrm{M}$ & OS & Subfov & Class & MCP & 41 & 28 & 4 & 0.4 & 1.5 & -11 & 500 & 4000 & 800 & 4000 & 500 \\
\hline & & & & $\mathrm{n}=16$ & Mean (SD) & $34(24)$ & $\begin{array}{l}19.7 \\
(8.7)\end{array}$ & $\begin{array}{c}2.2 \\
(1.3)\end{array}$ & $\begin{array}{c}0.60 \\
(0.35)\end{array}$ & $\begin{array}{c}0.49 \\
(0.39)\end{array}$ & $\begin{array}{c}1.1 \\
(4.1)\end{array}$ & $\begin{array}{l}1722 \\
(864)\end{array}$ & $\begin{array}{l}2836^{* *} \\
(1118)\end{array}$ & $\begin{array}{c}2119 \\
(1251)\end{array}$ & $\begin{array}{c}1963 \\
(1387)\end{array}$ & $\begin{array}{c}1625 \\
(1300)\end{array}$ \\
\hline
\end{tabular}

Mean values (SD) are indicated in bold. Mean values of the total cohort $(n=16)$ are shown below.

*Patient 15 received systemic steroid treatment during 3 months after first PDT.

$\uparrow$ Patient 16 received long-term systemic steroid treatment and one intravitreal injection the day after first PDT.

** $p>0.05$ (paired two-sided Student t test).

$\mathrm{B}$, bilateral choroidal neovascularisation; class, classic CNV subtype; CLD, neovascularisation lesion dimension; CNV, choroidal neovascularisation; fov, foveal; GLD, greatest linear lesion dimension; M/F, male/female; OD/OS, study eye, oculus dexter/sinister; PLD, pigment epithelial lesion dimension; Pt. no., patient number; Toxo, toxoplasmosis; VA, visual acuity. 
Figure 1 (A) $\log (M A R)$ visual acuity (VA) before treatment and at the end of observation $(n=16)$. The subgroups are separated by the indicated signs. (B) Changes in mean $\log (\mathrm{MAR})$ visual acuity during the follow-up period. Values represent the mean (SEM) and show increased vision during follow-up after a mean of 2.2 (1.3) photodynamic therapy using verteporfin (PDT) sessions per patient. For details, refer to table 1. MCP, multifocal choroiditis and panuveitis; POHS, presumed ocular histoplasmosis syndrome.
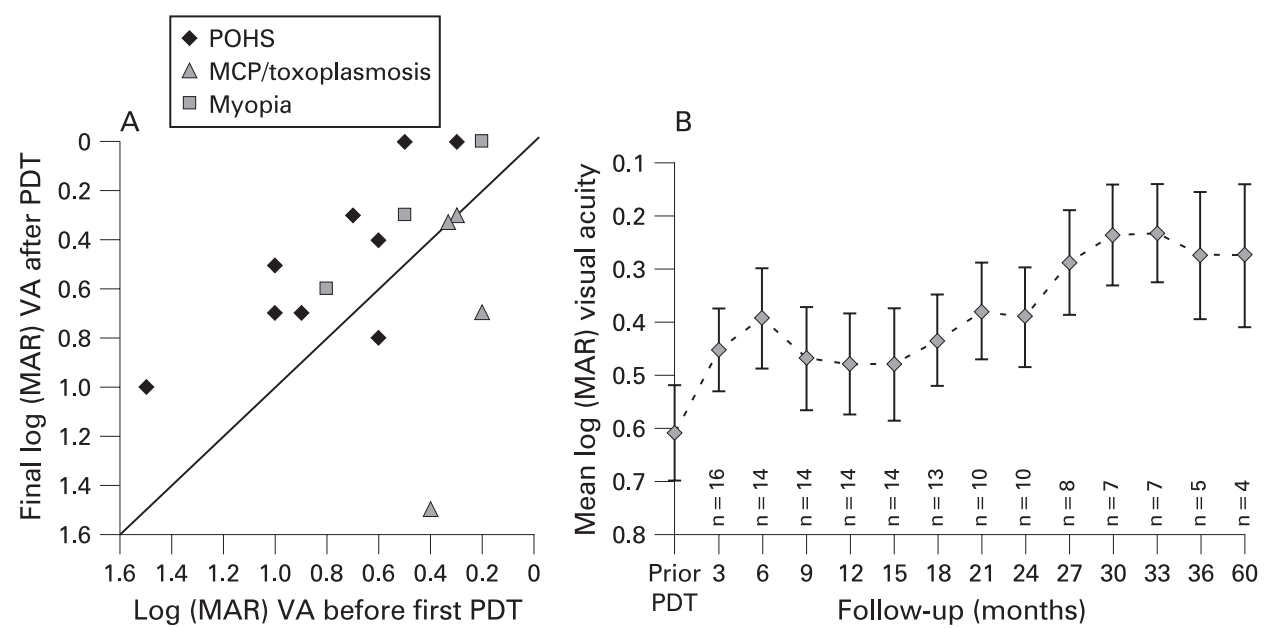

\section{POHS}

In the POHS subgroup, VA increased statistically significantly from $\log (\mathrm{MAR})=0.79(0.33)$ before the first PDT to $0.49(0.33)$ $(+2.80$ (2.15) lines) during follow-up of 28 (26) months $(\mathrm{p}=0.0038, \mathrm{n}=9)$. Patients in this subgroup received $1.7(0.8)$ PDT sessions during 28 (26) months (or 0.72 (0.38) PDTs per year). Three patients with POHS gained two lines of VA, two patients gained three lines, and three patients gained four to six lines at the end of follow-up. One patient lost two lines after one PDT session and denied further treatment, although the lesion still showed (reduced) leakage during angiography.

\section{Pathological myopia}

In the subgroup of three patients with CNV due to pathological myopia, subjects unexceptionally gained two lines each. During the follow-up period of 46 (22) months, patients received a mean of 1.7 (1.3) PDTs (or 0.45 (0.66) PDTs per year).

After combined analysis of patients with CNV related to POHS and pathological myopia, vision after 33 (27) months increased, statistically significantly, by 2.6 (2.0) lines from mean $\log (\mathrm{MAR}) 0.72(0.34)$ to $0.44(0.32)(\mathrm{p}=0.0005, \mathrm{n}=12)$. In this combined group, the mean PDT application number was 1.67 (0.87) (or 0.62 (0.39) PDT sessions per year).

\section{Toxoplasmosis/MCP}

A mean of 3.8 (1.1) PDT sessions were applied during 38 (14) months (corresponding to 1.20 (0.93) PDT sessions per year). Two patients with toxoplasmosis-related CNV after 38 (14) months follow-up revealed stable vision. Two patients with CNV secondary to MCP sustained decreases of five and 11 chart lines, respectively. Both patients were additionally treated with systemic steroid, and patient no. 13 once received an intravitreal injection of $4 \mathrm{mg}$ of triamcinolone acetate 1 day after initial PDT (table 1). No further patients underwent steroidal treatment. In patient $13, \mathrm{CNV}$ growth continued despite the application of four PDTs and additional steroidal systemic and intravitreal treatment.

\section{Lesion parameters}

Table 1 further depicts lesion parameters of the patients before treatment and at the end of follow-up. All CNV lesions were of the classic type. Lesion localisation was sub- or juxtafoveal in all but two patients. One patient with toxoplasmosis-related CNV exhibited a vision-limiting foveal scar with extrafoveal localisation of the CNV. In one further patient with myopic extrafoveal CNV, the initial vision loss was related to sub- and intraretinal fluid involving the fovea.

CNV inactivation was achieved in all except for three patients (81\%) as documented by fluorescein angiography. Two POHS patients declined further treatment and were lost to follow-up 3 and 6 months after initial PDT. Both patients responded to treatment with reduced GLD and leakage activity during angiography. As only one single patient with MCP (no. 13) exhibited CNV lesion growth and leakage despite four PDT administrations and additional steroidal systemic and intravitreal treatment, the rate of non-responding was $1 / 16=6 \%$.

In four patients $(25 \%)$, the contralateral eye showed CNV formation. In three out of these four patients, no treatment efforts were necessary as lesions revealed no leakage activity during follow-up. Visual acuity of the fellow eyes with inactive CNV was at stable $0.7 \log (\mathrm{MAR})$ during the observation interval without treatment. The fellow eye of one myopic patient with active extrafoveal CNV retained full vision after thermal photocoagulation.

The mean diameters of pigment epithelial alteration (PLD) increased, statistically significantly, by $40 \%$ during the observation period (from 1722 (864) $\mu \mathrm{m}$ before first PDT to 2836 (1118) $\mu \mathrm{m}$ mean (SD) at the end of follow-up; $p=0.0002$; $\mathrm{n}=16$ ). PLD differences before and after PDT remained statistically significant in the subgroup analyses. Analysis of the mean greatest linear dimensions (GLD) did not evince significant differences during follow-up.

However, courses of visual acuity showed no correlation with changes in PLD or GLD. Only in the MCP subgroup was the prevalent lesion growth accompanied by decreased vision $(r=0.99)$. Figure 2 depicts GLD values before and after therapy, and clearly shows the divergent GLD courses of the patients in the subgroups.

The cases shown in fig 3 represent positive and negative examples of treatment results. Although in both patients significant changes in pigment epithelial layer are represented by stippled window defects surrounding the CNV lesion during angiography, only patient no. 15 sustained vision loss as well as increased GLD. The CNV revealed no leakage activity after therapy in both cases (table 1, fig 3).

Figure 4 correlates changes in vision with PDT administration numbers. Patients in the POHS and myopia subgroups did not sustain major vision decreases after two or three PDT administrations. Conversely, two MCP patients significantly 


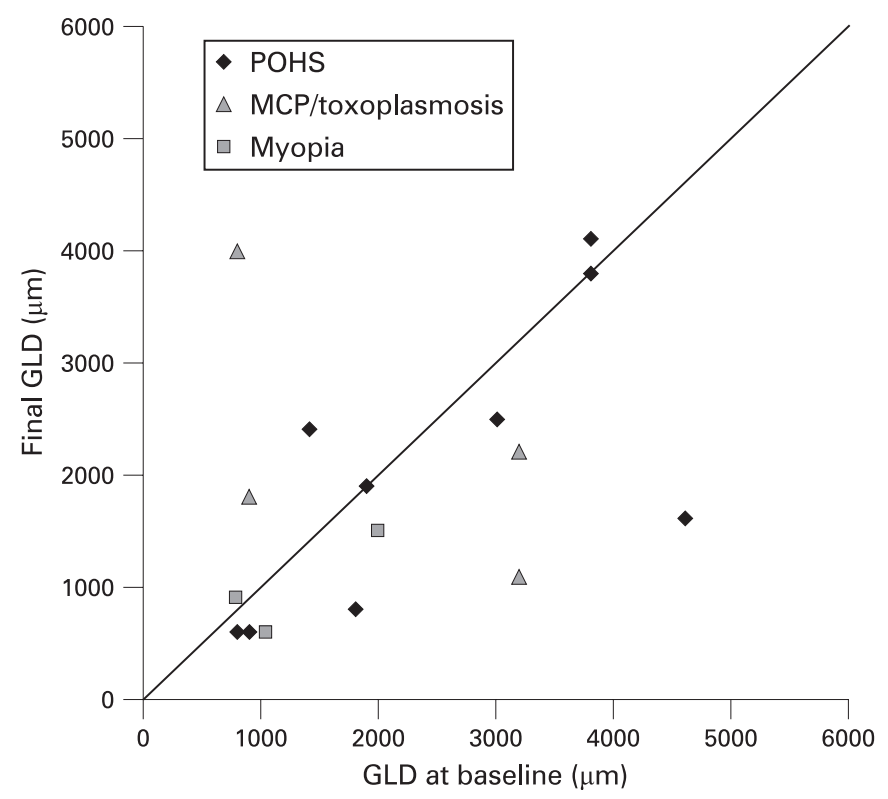

Figure 2 Greatest linear lesion dimensions (GLD) of the patients before and after 34.4 (24) months at the end of the observation. MCP, multifocal choroiditis and panuveitis; POHS, presumed ocular histoplasmosis syndrome. lost vision after four PDT sessions. One patient with toxoplasmosis-related CNV retained stable vision even after five PDT sessions. Neither final vision nor vision changes during the observation period correlated with PDT application frequency (data not shown).

\section{DISCUSSION}

The results indicate good if not excellent efficacy and tolerability which were most promising in a subgroup of patients with vision-impairing CNV not associated with active uveitis. With intent to surpass age inconsistencies within our collective, we separately analysed the seven paediatric patients from all disease entities. This evinced significant vision increases after 2.4 PDT sessions and 37 months of follow-up in this subgroup.

Sickenberg and co-workers were the first to report on beneficial results after PDT in subfoveal CNV lesions due to other reasons than age-related macular degeneration. ${ }^{13}$ Then, the Verteporfin in Ocular Histoplasmosis Study Group (VOHS) after 24 months achieved a median vision gain of 1.2 lines in a cohort with a median age of 50 at initial PDT. ${ }^{7}$ Several further studies recorded vision improvements after PDT of idiopathic $\mathrm{CNV}$ and CNV secondary to chorioretinal inflammation including POHS. ${ }^{14} 15$ 28-35 Although published data on PDT for $\mathrm{CNV}$ attributable to MCP suggest favourable results, ${ }^{32}{ }^{33}$ our
Figure $3(A-F)$ Left eye red-free fundus photography $(A)$, fundus autofluorescence (D) and angiography $(B, C, E, F)$ of patient no. 8 with choroidal neovascularisation (CNV) related to presumed ocular histoplasmosis syndrome before $(\mathrm{A}-\mathrm{C})$ and after one photodynamic therapy using verteporfin (PDT) session/ 62 months later (D-F). Vision increased by five lines. $(G-L)$ Left eye red-free fundus photography $(G, J)$ and angiography $(\mathrm{H}, \mathrm{I}, \mathrm{K}, \mathrm{L})$ of patient no. 15 with CNV related to multifocal choroiditis and panuveitis before (G-I) and after 21 months/four PDT sessions ( $\mathrm{J}-\mathrm{L}$ ). Vision decreased by five lines.
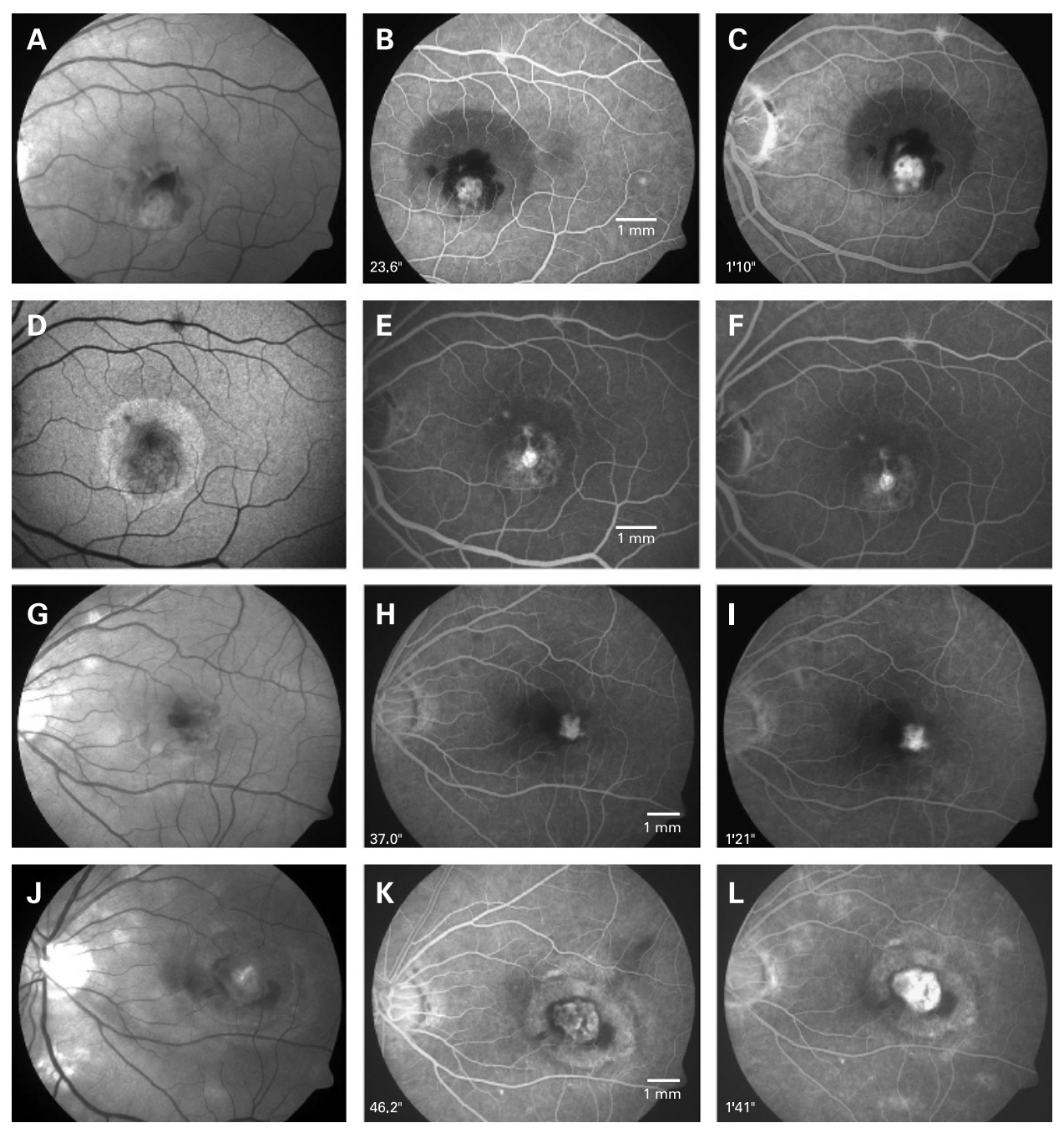


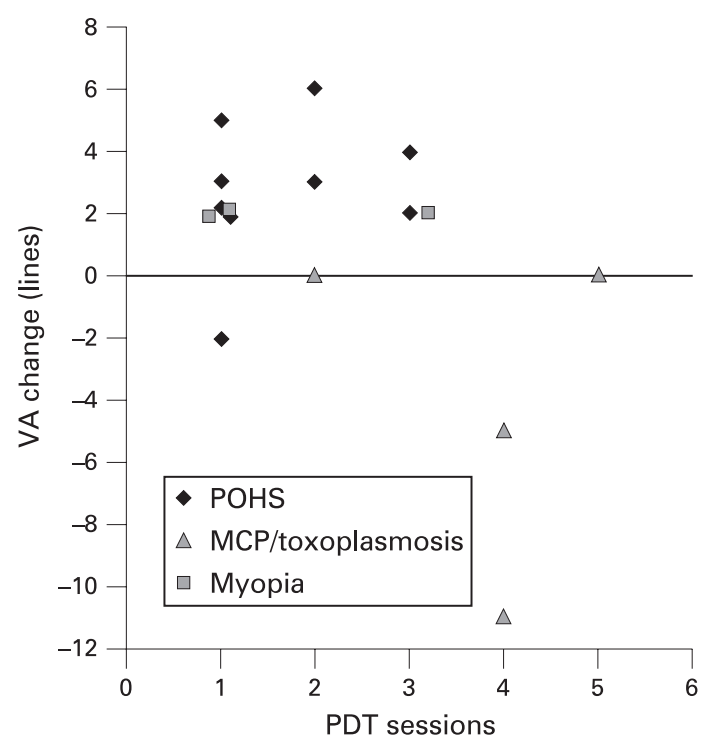

Figure 4 Relation of change in visual acuity and PDT session numbers in the subgroups. Patients who received two or more PDT administrations were not predetermined to sustain vision loss $(n=16)$.

experience with PDT in inflammatory CNV in young patients is limited. Within this series, two patients with MCP sustained significant vision decreases as well as increases in lesion size. Even since corticosteroidal supplementation fails to explain the courses, our case observations point to possible disease inhomogeneities leading to treatment failures in this disease group.

Congruent with a recent report on PDT in young individuals with CNV secondary to toxoplasmotic retinochoroiditis, ${ }^{34}$ our likewise affected patients had stable 20/40 vision after PDT and 23 or 59 months of follow-up, respectively. Probably due to the lesion location, vision was better in both of our patients when compared with cases reported in the study.

Successful PDT treatment of CNV in patients with pathological myopia was outlined in prospective randomised multicentre trials for subfoveal ${ }^{21}$ as well as in retrospective analyses for non-subfoveal CNV. ${ }^{22}$ Favourable results of PDT treatment of extrafoveal CNV in myopic patients were reported in a small case series by Gelisken and associates after a follow-up period of 36 months. ${ }^{23}$ In the present study, two CNV lesions with vision-impairing extrafoveal location were included (patient no. 12 and 14). In both cases, laser photocoagulation would have been an alternative ${ }^{11}{ }^{12}$ which was indeed used in the second eye of the myopic patient no. 12 with bilateral extrafoveal CNV. Here, full vision was retained after argon laser coagulation of the lesion during 24 months of observation. Since the PDT treatet study eye recovered full vision after one PDT session during 35 months and since the PDT scar remained stable in contrast to expanded size in the fellow eye, PDT treatment remains a reasonable alternative in this case. Notably, without considering treatment courses of patients with extrafoveal $\mathrm{CNV}$, vision results after PDT for $\mathrm{CNV}$ due to $\mathrm{POHS}$ and myopia significantly improved from $0.76(0.31)$ to $0.48(0.30)$ $(\mathrm{p}=0.001, \mathrm{n}=11)$.

Consistent positive PDT effects on CNV cessation in paediatric patients were shown in limited further case series. Although treatment regimes as well as CNV causes differed, the treatment safety and efficacy of PDT were affirmed in all cases. ${ }^{5} 63536$
One side-effect of PDT in young patients could result from the appearance of circumscribed pigment epithelial alteration and atrophy phenomena most probably arising from damage induced in the area of the laser spot. The presumed mechanism of verteporfin uptake by the retinal pigment epithelium and direct light activation may vary with age and thus be increased in young individuals. The significance of the atrophy phenomenon after PDT was highlighted by histochemical analyses in animal models and enucleated eyes s6-38 $^{36}$ well as in clinical observervations. ${ }^{5}{ }^{615} 39$ However, vision was unaffected during up to 3 years of observation. ${ }^{536}$ Four of five paediatric patients in the series of Giansanti and associates showed pigment epithelial atrophy in the area of the laser spot which did not lead to vision loss. ${ }^{6}$ In the study by Wachtlin et al, two paediatric patients with idiopathic CNV 13 and 22 months after PDT revealed no RPE reaction, ${ }^{15}$ but Mimouni reported on three paediatric cases with idiopathic CNV and treatment with PDT, of which at least one showed the typical RPE change. ${ }^{5}$ In our series, four of the seven paediatric patients (57\%) and eight of 16 cases in the total collective $(50 \%)$ revealed gradually different forms of pigment epithelial alteration with variations in shape and size. Thus, the mean pigment epithelial lesion diameters (PLD) increased by $40 \%$, which did not show a correlation with changes in vision. Notably, most lesions remained stable after therapy. Furthermore, compensation mechanisms have to be postulated, as RPE disturbances did not influence vision outcomes. Further investigations should be addressed on alterations of the pigment epithelium secondary to PDT in young patients as the outstanding side-effect in this study.

New treatment approaches of intravitreal pharmacotherapy using VEGF-binding substances in POHS or pathological myopia are promising. Nevertheless, the results still remain to be followed over a longer period. ${ }^{16-18}$ The probable necessity to maintain effective intravitreal concentrations over a longer period yet implies sustained intravitreal injections. However, Chan and associates reported an absence of leakage 3 months after three monthly injections of bevacizumab in $100 \%$ of 15 patients with CNV attributable to pigmented inner choroidopathy, central serous choroidopathy or idiopathic origin. ${ }^{19}$ Different to adults, paediatric patients may be able to stand the procedure of intravitreal injections only after sedation or anaesthesia. The cumulative risk of adverse events related to the injection procedure is another disadvantage compared with PDT in young patients.

PDT in this study provides good efficacy and safety in the treatment of paediatric and young adult patients with CNV attributable to $\mathrm{POHS}$ or pathological myopia. Although in our study only two patients with MCP responded unfavourably to PDT, non-responding may increasingly occur with a larger subset of patients and intravitreal injections of anti-VEGF substances may be administered in cases of resistance to photodynamic monotherapy. ${ }^{18}$

Funding: University Eye Clinic, Essen.

Competing interests: None.

Ethics approval: The design of the study was reviewed by the authors and the institutional review board. All procedures were in full accordance with local ethics board requirements.

\section{REFERENCES}

1. Spaide RF. Choroidal neovascularization in younger patients. Curr Opin Ophthalmol 1999;10:177-81.

2. Cohen SY, Laroche A, Leguen $Y$, et al. Etiology of choroidal neovascularization in young patients. Ophthalmology 1996;103:1241-4. 
3. Lindblom B, Andersson. The prognosis of idiopathic choroidal neovascularization in persons younger than 50 years of age. Ophthalmology 1998;105:1816-20.

4. Muller-Velten R, Michels S, Schmidt-Erfurth, et al. Photodynamic therapy: extended indication. Ophthalmologe 2003:100:384-90.

5. Mimouni KF, Bressler SB, Bressler NM. Photodynamic therapy with verteporfin for subfoveal choroidal neovascularization in children. Am J Ophthalmol 2003;135:900-2.

6. Giansanti F, Virgili G, Varano $\mathrm{M}$, et al. Photodynamic therapy for choroidal neovascularization in pediatric patients. Retina 2005;25:590-6.

7. Rosenfeld PJ, Saperstein DA, Bressler NM, et al. Verteporfin in Ocular Histoplasmosis Study Group. Photodynamic therapy with verteporfin in ocular histoplasmosis: uncontrolled, open-label 2-year study. Ophthalmology 2004;111:1725-33.

8. Gass JD, Wilkinson CP. Follow-up study of presumed ocular histoplasmosis. Trans Am Acad Ophthalmol Otolaryngol 1972;76:672-94

9. Hawkins BS, Bressler NM, Bressler SB, et al. Surgical removal vs observation for subfoveal choroidal neovascularization, either associated with the ocular histoplasmosis syndrome or idiopathic: I. Ophthalmic findings from a randomized clinical trial: Submacular Surgery Trials (SST) Group H Trial: SST Report No. 9. Arch Ophthalmol 2004;122:1597-611.

10. Macular Photocoagulation Study Group. Argon laser photocoagulation for neovascular maculopathy. Five-year results from randomized clinical trials. Arch Ophthalmol 1991;109:1109-14.

11. Macular Photocoagulation Study Group. Laser photocoagulation for juxtafovea choroidal neovascularization. Five-year results from randomized clinical trials. Arch Ophthalmol 1994;112:500-9.

12. Macular Photocoagulation Study Group. Five year follow-up of fellow eyes of individuals with ocular histoplasmosis and unilateral extrafoveal or juxtafoveal choroidal neovascularization. Arch Ophthalmol 1996;114:677.

13. Sickenberg M, Schmidt-Erfurth U, Miller JW, et al. A preliminary study of photodynamic therapy using verteporfin for choroidal neovascularization in pathologic myopia, ocular histoplasmosis syndrome, angioid streaks, and idiopathic causes. Arch Ophthalmol 2000:118:327-36.

14. Wachtlin J, Heimann H, Behme T, et al. Long-term results after photodynamic therapy with verteporfin for choroidal neovascularizations secondary to inflammatory chorioretinal diseases. Graefes Arch Clin Exp Ophthalmol 2003;241:899-906.

15. Wachtlin J, Wehner A, Heimann H, et al. Photodynamic treatment with verteporfin for patients with idiopathic choroidal neovascularization. Two-year results. Ophthalmologe 2004;101:489-95.

16. Hernández-Rojas ML, Quiroz-Mercado H, Dalma-Weiszhausz J, et al. Short-term effects of intravitreal bevacizumab for subfoveal choroidal neovascularization in pathologic myopia. Retina 2007;27:707-12.

17. Chan WM, Lai TY, Liu DT, et al. Intravitreal bevacizumab (avastin) for myopic choroidal neovascularization. Six-month results of a prospective pilot study. Ophthalmology 2007;114:2190-6.

18. Schadlu R. Intravitreal bevacizumab (Avastin) treatment of choroida neovascularisations secondary to the ocular histoplasmosis syndrome. IOVS 2007; 48:E-Abstract 1458

19. Chan WM, Lai TY, Liu DT, et al. Intravitreal bevacizumab (avastin) for choroida neovascularization secondary to central serous chorioretinopathy, secondary to punctate inner choroidopathy, or of idiopathic origin. Am J Ophthalmol 2007:143:977-83.

20. O'Toole L, Tufail A, Pavesio C. Management of choroidal neovascularization in uveitis. Int Ophthalmol Clin 2005:45:157-77.

21. Blinder KJ, Blumenkranz MS, Bressler NM, et al. Verteporfin therapy of subfovea choroidal neovascularization in pathologic myopia: 2-year results of a randomized clinical trial-VIP report no. 3. Ophthalmology 2003:110:667-73.
22. Virgili G, Varano M, Giacomelli G, et al. Photodynamic therapy for nonsubfoveal choroidal neovascularization in 100 eyes with pathologic myopia. Am J Ophthalmol 2007:143:77-82

23. Gelisken F, Inhoffen W, Hermann A, et al. Verteporfin photodynamic therapy for extrafoveal choroidal neovascularisation in pathologic myopia. Graefes Arch Clin Exp Ophthalmol 2004;242:926-30.

24. Azab M, Benchaboune M, Blinder KJ, et al. Verteporfin therapy of subfoveal choroidal neovascularization in age-related macular degeneration: meta-analysis of 2 year safety results in three randomized clinical trials: treatment of age-related macular degeneration with photodynamic therapy and verteporfin in photodynamic therapy study report no. 4. Retina 2004;24:1-12

25. Jurklies B, Bornfeld N, Schilling $\mathrm{H}$. Photodynamic therapy using verteporfin for choroidal neovascularization associated with angioid streaks-long-term effects. Ophthalmic Res 2006:38:209-17.

26. Jurklies B, Anastassiou G, Ortmans $\mathrm{S}$, et al. Photodynamic therapy using verteporfin in circumscribed choroidal haemangioma. Br J Ophthalmol 2003;87:84-9.

27. Chamberlin JA, Bressler NM, Bressler SB, et al. The use of fundus photographs and fluorescein angiograms in the identification and treatment of choroidal neovascularization in the Macular Photocoagulation Study. Ophthalmology 1989:96:1526-34

28. Yoo MH, Boo HD, Kim HK. Result of photodynamic therapy for idiopathic subfoveal choroidal neovascularization. Korean J Ophthalmol 2005;19:264-8.

29. Rogers AH, Duker JS, Nichols N, et al. Photodynamic therapy of idiopathic and inflammatory choroidal neovascularization in young adults. Ophthalmology 2003:110:1315-20.

30. Busquets MA, Shah GK, Wickens J, et al. Ocular photodynamic therapy with verteporfin for choroidal neovascularization secondary to ocular histoplasmosis syndrome. Retina 2003;23:299-306.

31. Spaide RF, Martin ML, Slakter J, et al. Treatment of idiopathic subfoveal choroidal neovascular lesions using photodynamic therapy with verteporfin. Am J Ophthalmol 2002; 134:62-8

32. Spaide RF, Freund KB, Slakter J, et al. Treatment of subfoveal choroidal neovascularization associated with multifocal choroiditis and panuveitis with photodynamic therapy. Retina 2002;22:545-9.

33. Gerth C, Spital G, Lommatzsch A, et al. Photodynamic therapy for choroidal neovascularization in patients with multifocal choroiditis and panuveitis. Eur J Ophthalmol 2006:16:111-8.

34. Mauget-Faysse M, Mimoun G, Ruiz-Moreno JM, et al. Verteporfin photodynamic therapy for choroidal neovascularization associated with toxoplasmic retinochoroiditis. Retina 2006:26:396-403.

35. Liu JC, Boldt HC, Folk JC, et al. Photodynamic therapy of subfoveal and juxtafoveal choroidal neovascularization in ocular histoplasmosis syndrome: a retrospective case series. Retina 2004;24:863-70.

36. Harissi-Dagher $\mathbf{M}$, Sebag M, Gauthier D, et al. Photodynamic therapy in young patients with choroidal neovascularization following traumatic choroidal rupture. Am J Ophthalmol 2005;139:726-8.

37. Haimovici R, Kramer M, Miller JW, et al. Localization of lipoprotein-delivered benzoporphyrin derivative in the rabbit eye. Curr Eye Res 1997:16:83-90.

38. Schlotzer-Schrehardt U, Viestenz A, Naumann GO, et al. Dose-related structural effects of photodynamic therapy on choroidal and retinal structures of human eyes. Graefes Arch Clin Exp Ophthalmol 2003;240:748-57.

39. Postelmans L, Pasteels B, Coquelet P, et al. Severe pigment epithelial alterations in the treatment area following photodynamic therapy for classic choroidal neovascularization in young females. Am J Ophthalmol 2004;138: $803-8$. 